\title{
Levantamento de marsupiais e roedores da área de proteção ambiental municipal Tartarugas - Anchieta, ES
}

A Mata Atlântica é um bioma altamente fragmentado e possui uma elevada diversidade de espécies, sendo muitas destas endêmicas. Apesar disto, no Estado do Espírito Santo, o conhecimento sobre a fauna de pequenos mamíferos não voadores ainda é pouco conhecido, principalmente no ecossistema restinga. As ordens Didelphimorphia e Rodentia, considerados pequenos mamíferos não voadores, compõem o grupo ecológico mais diversificado das Florestas Neotropicais. Por serem bioindicadores, estes sinalizam alterações do ambiente em que habitam e influenciam a dinâmica florestal. O presente estudo teve como objetivo apresenta um levantamento de pequenos marsupiais e roedores na restinga da Área de Preservação Ambiental (APA) municipal Tartarugas, no município de Anchieta, Estado do Espírito Santo. Os mamíferos foram capturados por meio das armadilhas Tomahawk, Sherman e pitfall. Por meio destas, foram coletadas 3 espécies de Didelphimorphias, sendo os indivíduos da espécie Marmosops incanus os mais abundantes, além de terem sido verificados 19 indivíduos da ordem Rodentia. A restinga da Área de Proteção Ambiental Municipal Tartarugas apresenta grande riqueza de pequenos marsupiais e roedores, tendo em vista possuir dimensõe pequenas e sofrer ações antrópicas ao seu entorno. Estudos sobre a riqueza e abundância destes animais na vegetação de restinga são escassos quando comparados a demais ecossistemas. Assim, um conhecimento maior destes animais nesta área facilita a compreensão da dinâmica e o funcionamento da qualidade ambiental realizada por estas espécies.

Palavras-chave: Mata atlântica; Pequenos mamíferos; Restinga.

\section{Survey of marsupials and rodents of the municipal environmental protection area Tartarugas - Anchieta, ES}

\begin{abstract}
The Atlantic Forest is a highly fragmented biome and has a high diversity of species, many of which are endemic. Despite this, in the State of Espírito Santo, the knowledge about the fauna of small non-flying mammals is still little known, mainly in the restinga ecosystem. The orders Didelphimorphia and Rodentia, considered small non-flying mammals, make up the most diverse ecological group in the Neotropical Forests. As bioindicators, they signal changes in the environment in which they live and influence forest dynamics. The present study aimed to present a survey of small marsupials and rodents in the restinga of the Tartarugas Municipal Environmental Preservation Area (APA), in the municipality of Anchieta, State of Espírito Santo. The mammals were captured using the Tomahawk, Sherman and pitfall traps. Through these, 3 species of Didelphimorphias were collected, with individuals of the species Marmosops incanus being the most abundant, in addition to 19 individuals of the order Rodentia having been verified. The sandbank of the Tartarugas Municipal Environmental Protection Area has a great wealth of small marsupials and rodents, with a view to having small dimensions and undergoing anthropic actions around them. Studies on the richness and abundance of these animals in restinga vegetation are scarce when compared to other ecosystems. Thus, a greater knowledge of these animals in this area facilitates the understanding of the dynamics and the functioning of the environmental quality performed by these species.
\end{abstract}

Keywords: Atlantic forest; Small mammals; Restinga.

Topic: Conservação da Biodiversidade

Reviewed anonymously in the process of blind peer
Received: $12 / 03 / 2020$

Approved: 11/04/2020
Fernanda Lourencine Paulo (iD

Universidade Norte do Paraná, Brasil

http://lattes.cnpq.br/1337042170381471

http://orcid.org/0000-0002-6803-8393

fernanda.iriri@hotmail.com

\section{Helimar Rabello (ID)}

Universidade Federal do Espírito Santo, Brasi

http://lattes.cnpq.br/3789680363736207

http://orcid.org/0000-0002-1699-595X

helimarbio@hotmail.com

Caio Henrique Ungarato Fiorese (id

Centro Universitário São Camilo, Brasil

http://lattes.cnpq.br/0545804621047516

http://orcid.org/0000-0001-6866-0361

caiofiorese@hotmail.com

d

DOI: 10.6008/CBPC2318-2881.2020.002.0003

\author{
Gilson Silva Filho \\ Centro Universitário São Camilo, Brasil \\ http://lattes.cnpq.br/1040363193594196 \\ http://orcid.org/0000-0001-5313-1424 \\ silva.filho.gilson@gmail.com \\ Cíntia Cristina Lima Teixeira \\ Centro Universitário São Camilo, Brasil \\ http://lattes.cnpq.br/2013098051038491 \\ https://orcid.org/0000-0002-8438-5897 \\ cintiateixeira@saocamilo-es.br \\ Gabrielli Machado Bindeli (iD \\ Centro Universitário São Camilo, Brasil \\ http://lattes.cnpq.br/3704712429916403 \\ http://orcid.org/0000-0002-3159-4046 \\ gabriellimbindeli@gmail.com
}

Referencing this:

PAULO, F. L. F.; RABELLO, H.; FIORESE, C. H. U.; SILVA FILHO, G.; TEIXEIRA, C. C. L.; BINDELI, G. M.. Levantamento de marsupiais e roedores da área de proteção ambiental municipal Tartarugas Anchieta, ES. Nature and Conservation, v.13, n.2, p.26-37, 2020. DOI: http://doi.org/10.6008/CBPC2318-2881.2020.002.0003 


\section{INTRODUÇÃO}

A Mata Atlântica é um conjunto de diferentes formações florestais que ocupa grande parte do território Brasileiro. Originalmente, cobria um total de 17 estados possuindo uma área de $1.300 .000 \mathrm{~km}^{2}$ aproximadamente (MMA, 2010; MMA, 2013). Considerado o bioma brasileiro mais reduzido devido ao grande crescimento dos índices de desmatamento ilegal, da extração madeireira, do crescimento populacional desordenado, da caça e pesca predatória e entre outros fatores (SANTOS et al., 2011), a Mata Atlântica está distribuída em diversos fragmentos e reduzida a aproximadamente $26 \%$ de sua cobertura vegetal nativa (MMA, 2013). Apesar disto, possui uma alta biodiversidade de fauna e flora, além de contribuir com a regulação do clima, com a proteção de mananciais hídricos e de encostas e beneficiar cerca de 120 milhões de brasileiros (MMA, 2010; MMA, 2013).

A Mata Atlântica, no estado do Espírito Santo, já apresentou 100\% da ocupação de sua superfície (MMA, 2010). Segundo dados da Fundação SOS Mata Atlântica e do Instituto Nacional de Pesquisas Espaciais (INPE, 2014), a cobertura da Mata Atlântica entre os anos de 2012 e 2013 foi de 10,5\%, onde 20 hectares foram desmatados. No Estado do Espírito Santo, a Mata Atlântica é composta pelas florestas ombrófila densa, ombrófila aberta e estacional semidecidual, por mangues, pelo refúgio vegetacional da Serra do Caparaó e restingas (MMA, 2010).

De acordo com a Resolução do Conselho Nacional do Meio Ambiente (CONAMA) no 10, de 1993, a restinga é uma vegetação que cobre o litoral Brasileiro e que recebe influência marítima. Também considerada comunidade edáfica, possui uma formação em mosaico e encontra-se em praias, cordões arenosos, dunas e depressões, podendo apresentar estrato herbáceo, arbustivo e arbóreo. A vegetação de restinga na Mata Atlântica equivale a 641.284 ha (SOSMA et al., 2014). As restingas possuem diferentes composições fisionômicas e fitofisionômicas devido às alterações nos aspectos geomorfológicas das planícies arenosas (LESSA et al., 2007). A restinga da APA Municipal Tartarugas possui uma fauna e flora que se encontram em um grau de conservação satisfatórios, com significativas áreas de restingas e matas de tabuleiro (EA, 2000). Entretanto, estudos sobre a fauna de pequenos mamíferos não voadores ainda são escassos, pois tais mamíferos são pouco ou até mesmo desconhecidos nesta região.

Comumente, define-se como 'pequeno mamífero' animais que possuem peso menor que cinco quilogramas. Porém, restringe-se ao termo apenas os marsupiais e roedores. Os pequenos mamíferos são animais que geralmente possuem hábitos noturnos, de forma que sua observação e sua captura para o estudo de sua ecologia se tornam trabalhoso (MMA, 2008).

O Brasil possui uma grande diversidade de mamíferos. São 652 espécies nativas, na qual 250 espécies incidem na Mata Atlântica, 65 são endêmicas (PASSAMANI, 2005) e distribuídas em 11 ordens (RABELLO et al., 2009). As ordens Didelphimorphia e Rodentia, considerados pequenos mamíferos não voadores (REIS et al., 2006), compõem o grupo ecológico mais diversificado das florestas neotropicais (PARDINI, 2006; PESSÔA, 2009).

A família Didelphidae, a única dentro da ordem Didelphimorphia, é composta por 17 gêneros e 87 
espécies. Os marsupiais desta família apresentam características, tais como: porte pequeno a médio, mãos e pés com cinco dedos, cauda geralmente longa e preênsil. A maioria possui hábitos noturnos e uma dieta onívora. As espécies desta ordem possuem o marsúpio, uma bolsa externa formada por uma dobra de pele que protege os filhotes em seu estágio de desenvolvimento (REIS et al., 2006).

Da ordem Rodentia, encontram-se, no Brasil, 74 gêneros e 236 espécies de roedores (BONVICINO et al., 2008). Estes animais possuem uma alimentação diversificada, podendo ser espécies herbívoras, carnívoras, insetívoras ou piscívoras. Possuem adaptações à vida arborícola, terrestre e fossória, além de viverem tanto em climas frios como quentes. A reprodução das espécies de pequeno porte varia de acordo com a oportunidade ao decorrer do ano (MONTES, 2003).

Para a ecologia, é fundamental abranger os conhecimentos sobre a riqueza e distribuição das espécies, na qual podem revelar a história e as relações ecológicas heterogênicas (PESSÔA, 2009). Portanto, o presente estudo teve como objetivo realizar um levantamento de pequenos marsupiais e roedores no ecossistema restinga localizado na APA Municipal Tartarugas, no município de Anchieta, Estado do Espírito Santo, devido estes mamíferos apresentarem importante papel na cadeia alimentar e na dispersão de sementes.

\section{MATERIAIS E MÉTODOS}

A Área de Proteção Ambiental (APA) Municipal Tartarugas situa-se na região sudeste no Estado do Espírito Santo, Brasil, mais precisamente na sede do Município de Anchieta, no Bairro Guanabara, nas coordenadas UTM 0331797 E/7696513 S. Situada à esquerda da Rodovia do Sol (ES-060), sentido do município de Guarapari para o de Anchieta. $\mathrm{O}$ acesso pode ser feito através da estrada de terra no sentido a localidade de Parati, estando a 6 km da sede do município.

A APA Municipal Tartarugas foi criada pela Prefeitura Municipal de Anchieta através da Lei Municipal no. 008 de 18 de Junho de 1998, com base no Art. 46, § 3 da Lei Orgânica Municipal e Art. 66, § 3o da Constituição Estadual, a fim de preservar a área destinada à desova de tartarugas marinhas (ANCHIETA, 1998). A APA possui duas áreas descontínuas ao logo da faixa litorânea. A área estudada possui uma extensão total de $2,4 \mathrm{~km}$, onde $500 \mathrm{~m}^{2}$ desta foi realizado o levantamento. A restinga da APA Municipal Tartarugas possui uma fauna e flora que se encontram em um grau de conservação satisfatórios, com significativas áreas de restingas e matas de tabuleiro. A Figura 1 mostra a vista aérea das áreas de restinga desse estudo.

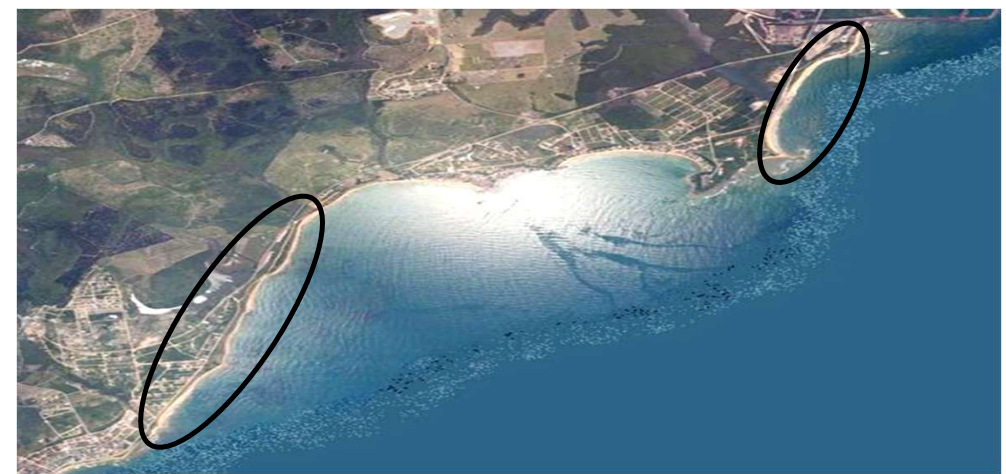

Figura 1: Vista aérea da restinga da área de proteção ambiental (APA) Municipal Tartarugas. 
A vegetação existente ao longo da APA é constituída por diferentes fitofisionomias, destacando-se halófila-psamófila/pós-praia, vegetação de transição e estágio inicial de regeneração da Floresta Atlântica (EA, 2000). Algumas espécies mais encontradas e que apresentam melhor desenvolvimento e crescimento, de acordo com o Plano de Manejo da Área (EA, 2000), foram: Schinus terebinthifolius Raddi (aroeiravermelha), Eugenia uniflora L. (pitanga vermelha), Jacquinia brasiliensis (GARCIA et al., 1994) (pimenteirada-praia), Sophora tomentosa L. (ervilha-da-praia), Senna australis (Vell.) H.S. Irwin \& Barneby (acáciaamarela-de-restinga), Psidium cattleianum Sabine (goiaba-de-restinga), Bromelia antiacantha Bertol (bromélia), Clusia spiritu-sanctensis G. Mariz \& B. Weinberg (abaneiro), Pilosocereus arrabidae Lem (cacto), Cereus fernambucensis Lem (cacto), Cocos nucifera Linn (coco) e entre outros. A Figura 2 apresenta a restinga da APA estudada.
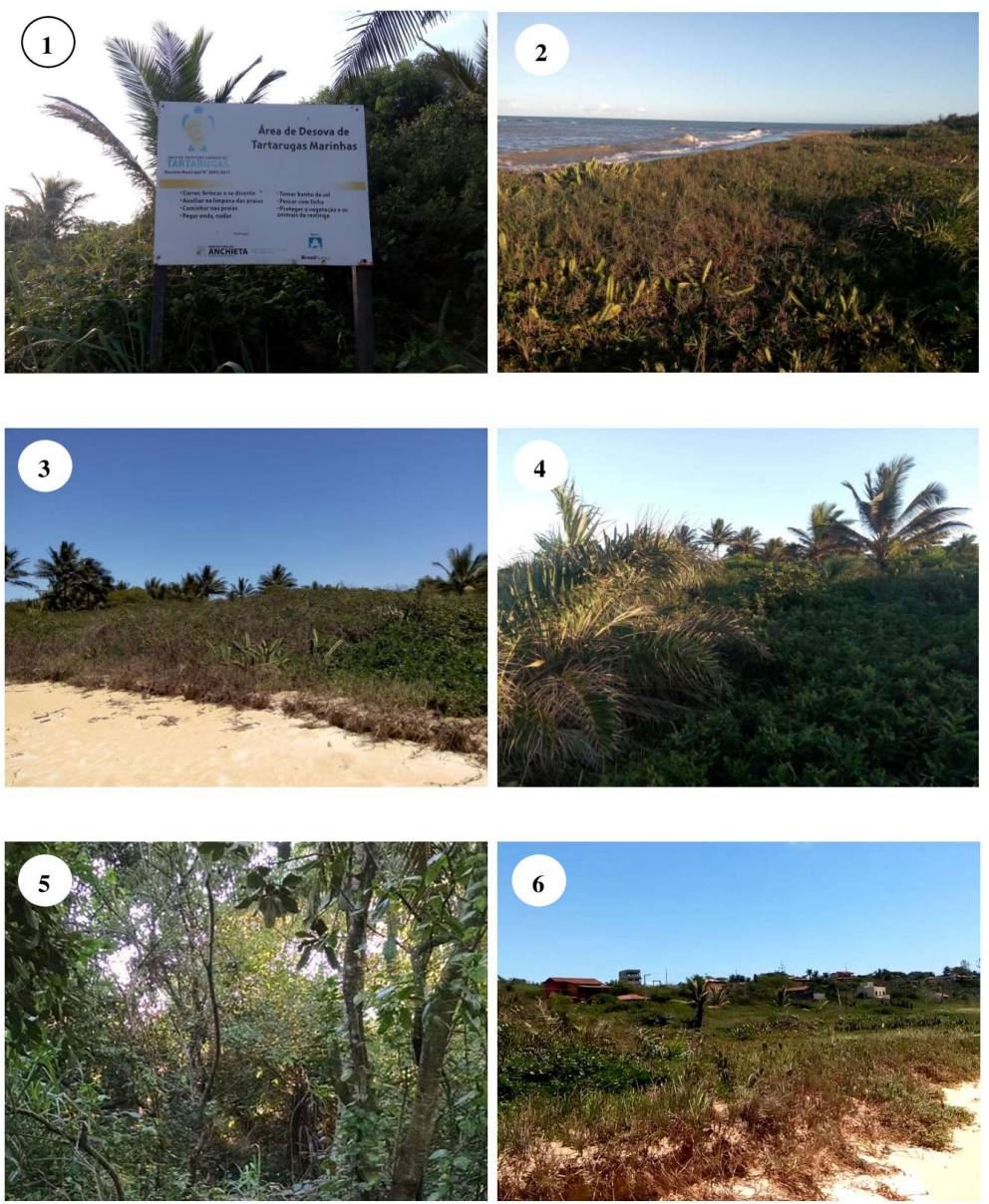

Figura 2: Restinga da APA Municipal Tartarugas. 1-Placa de identificação da área; 2,3- Vegetação herbácea fechada; 4Vegetação arbustiva; 5-Vegetação arbórea; 6- Vegetação herbácea e ocupação humana ao fundo.

A APA municipal Tartarugas, por se tratar de uma faixa litorânea, apresenta em seu entorno uma ocupação humana desordenada com residências de moradores, veraneios e pousadas, além de atividades industriais, como a do setor de mineração. O clima predominante da área é definido como quente e úmido, com estação chuvosa no verão e seca no inverno (EA, 2000).

As coletas das amostras dos pequenos marsupiais e roedores foram realizadas no período de abril a agosto de 2016, onde foram utilizadas 20 armadilhas montadas em quatro transectos lineares, sendo 04 do tipo Sherman $(25 \times 8 \times 9 \mathrm{~cm})$ posicionadas em vegetação arbustiva a uma altura de 1,60 $\mathrm{m}$ aproximadamente 
(T2), 11 do tipo Tomahawk $(45 \times 16 \times 16 \mathrm{~cm})$, onde 6 foram colocadas em vegetação arbórea (T1) e 05 em vegetação arbustiva (T3) e nas armadilhas de interceptação e queda (pitfall), que foram posicionadas em vegetação herbácea. Foram utilizados cinco baldes de 40 litros, sendo que estes foram enterrados no solo de forma linear (T4) (Figura 3). Cada balde possuía uma distância de 3 metros um do outro e pequenos furos no fundo para impedir grande entrada e acúmulo de água em períodos de chuva.

As armadilhas Tomahawks e Sherman tiveram um espaçamento de 10 metros umas das outras e entre os transectos T1 e T2, o espaçamento foi de $20 \mathrm{~m}$. Entre T2 e T3, o espaçamento foi de 70m e $20 \mathrm{~m}$ entre os transectos T3 e T4 (Figura 3). Estas foram mantidas na mesma localização durante todo o período de amostragem, onde foram colocadas aos domingos ao anoitecer e vistoriadas as segundas ao amanhecer e, posteriormente, recolhidas (Sherman e Tomahawk, pitfalls foram tampadas) após este horário.

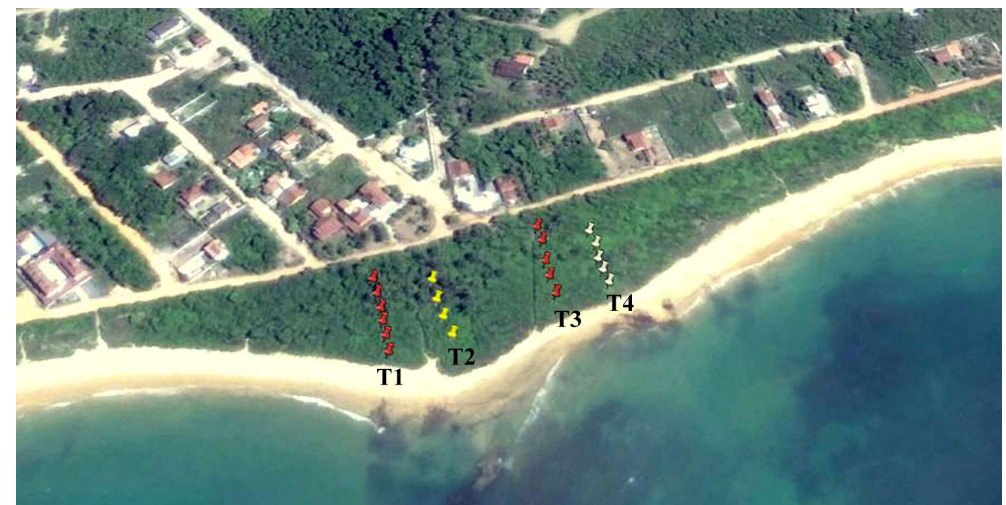

Figura 3: Localização das armadilhas nos transectos: T1, T3-armadilhas Tomahawk; T2- armadilhas Sherman; T4armadilhas pitfall.

As armadilhas foram iscadas com banana e uma mistura composta por banana, farinha de milho, amendoim triturado e óleo de sardinha. Apenas um tipo de isca foi utilizado em cada armadilha. O método utilizado para a coleta foi o de captura-marcação-recaptura, e os indivíduos capturados foram marcados com corte no pelo, fotografados, identificados e soltos no mesmo ponto onde foram capturados. Os dados relacionados ao sexo, tipo de isca e armadilha em que cada indivíduo foi capturado, foram coletados (Figura 4). Grande parte das espécies neotropicais de roedores apresentam ampla dificuldade de identificação, sendo a observação das características do crânio necessárias. Por esta razão, não foi possível identificar os indivíduos da ordem Rodentia.

Foram calculadas a frequência de ocorrência (FO) e de abundância relativa (AR) das espécies. Em FO, dividiu-se o número de registros da espécie durante todas as campanhas pela quantidade de campanhas e multiplicou-se por 100. Em AR, em termos percentuais, foi calculada a abundância relativa de cada espécie dentro do grupo, que equivale à proporção de registros de uma espécie com relação ao total de registros de todas as espécies. Para o cálculo, dividiu-se o número de indivíduos de uma determinada espécie pelo número total de todos os indivíduos encontrados ao final de todas as campanhas e dividiu este resultado por 100. Esses dados, além de darem base para o cálculo dos índices de diversidade, são importantes na determinação da qualidade e do equilíbrio do ambiente. 

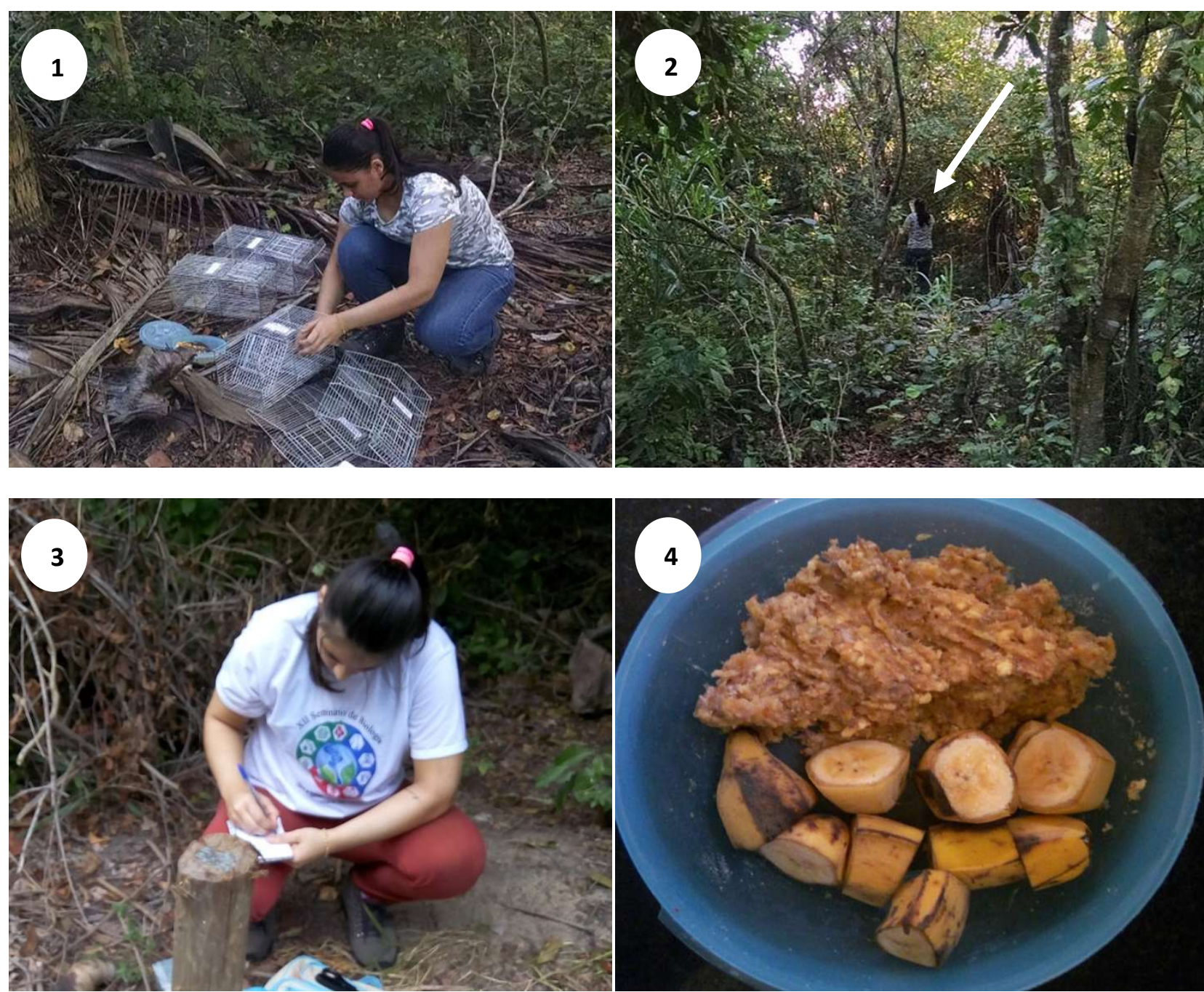

Figura 4: 1- Montagem das armadilhas Tomahawk; 2- Colocação das armadilhas; 3- Coleta dos dados dos pequenos mamíferos; 4- Iscas: mistura e banana.

A diversidade dos pequenos mamíferos foi mensurada através do índice de Shannon-Weaver. Este é utilizado para amostras aleatórias de espécies de uma comunidade ou subcomunidade de interesse, e é estimado pela equação:

$$
\mathrm{H}^{\prime}=-\sum\left(p_{\mathrm{i}} \ln p_{\mathrm{i}}\right)
$$

Onde: pi = é a proporção da espécie em relação ao número total de espécimes inventariadas e; In= logaritmo neperiano.

Para a curva do coletor dos diferentes indivíduos deste estudo, utilizou-se o método de rarefação com o cálculo de intervalo de confiança de $95 \%$, onde quanto maior o esforço amostral, maior é a representatividade da amostra. A rarefação baseada em amostras (curva de acumulação de espécies) é aplicada quando uma dada quantidade de amostras é disponível, a partir das quais a riqueza de espécies é estimada como função do número de amostras. A partir dos registros das espécies feitos em campo, o método de rarefação apresenta a curva do coletor e realiza a estimativa máxima e mínima de espécies que poderiam ter sido registradas com o mesmo esforço. E, conforme as amostras são feitas, diminui-se o número de espécies a serem acrescentadas, até que a curva se aproxime da estabilização.

Foi calculado, para a distribuição dos indivíduos entre as espécies, o índice de equitabilidade de Pielou (J). Este índice é calculado a partir da seguinte equação:

$$
\mathrm{J}=\mathrm{H}^{\prime} / \mathrm{H}^{\prime} \mathrm{MAX} \text {; }
$$


Onde: $H^{\prime}$ = índice de Shannon- Wiener. Já H'MAX é obtido a partir da seguinte equação: $H^{\prime} M A X=\log S$

Onde: $\mathrm{S}$ = número total de espécies.

Para estimar a riqueza de espécies na área, utilizaram-se os estimadores Jackknife de 1a ordem e Chao de 2a ordem. Em Jackknife 1, este é calculado pela equação:

$$
\text { Jack1 }=\text { Sobs }+Q 1(m-1 / m)
$$

Onde: Sobs = é o número de total de espécies observadas; Q1 = é o número de unicatas e; $\mathrm{m}=$ é o número de amostras. Já o estimador Chao 2 foi calculado pela equação: Chao 2 = Sobs $+\left(Q_{1}^{2} / 2 Q 2\right)$

Onde: Sobs = é o número de total de espécies observadas; Q1 = é a frequência de unicatas e; Q2 = é a frequência de duplicatas. A curva do coletor, os estimadores de riqueza e os índices de diversidade e equitabilidade foram realizados com o programa de software PAST versão 1.91.

\section{RESULTADOS E DISCUSSÃO}

Em um período de 5 meses de pesquisa de campo (abril a agosto do ano de 2016) e um esforço de captura de 6.300 armadilhas/horas, foram registrados, na APA Municipal Tartarugas, treze indivíduos da ordem Didelphimorphia, divididos em 3 espécies Marmosa murina, Marmosops incanus e Didelphis aurita e 19 indivíduos da ordem Rodentia (sendo todos ratos), com um total de 79 capturas de 45 indivíduos. Conforme a tabela de frequência de ocorrência (FO) e abundância relativa (AR) dos mamíferos (Tabela 1), a ordem Rodentia foi a mais frequente e a mais abundante, com uma frequência de ocorrência de 152,38\% e abundância de 42,22\%. Em relação a ordem Didelphimorphia, Marmosops incanus, está apresentou uma FO de $123,80 \%$ e AR de 17,77\%, seguida de Marmosa murina (FO 33,33; AR 8,88), e Didelphis aurita (FO 9,52; AR 2,22). Na área, também foi capturado o primata Calithrix penicillata (FO 47,61; AR 13,33).

Tabela 1: Classe de Frequência; MF: Muito Frequente/ Abundância; A: Abundante/ MA: Muito Abundante/ Classe de Abundância; A: Abundante/ C: Comum.

\begin{tabular}{|c|c|c|c|c|c|c|c|}
\hline $\begin{array}{l}\text { Espécies/ Ordem } \\
\text { encontrada }\end{array}$ & $\begin{array}{l}\text { № de } \\
\text { indivíduo }\end{array}$ & $\begin{array}{l}\text { № de } \\
\text { encontros }\end{array}$ & $\begin{array}{l}\text { Freq. de } \\
\text { ocorrência } \\
\text { (FO) }\end{array}$ & $\begin{array}{l}\text { Classe } \\
\text { Frequência }\end{array}$ & $\begin{array}{l}\text { Abundância } \\
\text { Relativa } \\
\text { (AR) }\end{array}$ & Abundância & $\begin{array}{l}\text { Classe de } \\
\text { Abundância } \\
\text { (CTA) }\end{array}$ \\
\hline Marmosa murina & 4 & 7 & 33,33 & $\mathrm{MF}$ & 8,88 & MA & $A$ \\
\hline Marmosops incanus & 8 & 26 & 123,80 & $\mathrm{MF}$ & 17,77 & MA & A \\
\hline Didelphis aurita & 1 & 2 & 9,52 & $\mathrm{MF}$ & 2,22 & A & $\mathrm{C}$ \\
\hline Rodentia & 19 & 32 & 152,38 & $\mathrm{MF}$ & 42,22 & MA & $\mathrm{A}$ \\
\hline Calithrix penicillata & 6 & 10 & 47,61 & MF & 13,33 & MA & A \\
\hline
\end{tabular}

Com relação à riqueza das espécies, o estimador Jackknife de 1aordem avaliou o número máximo de 5,95 de riqueza, enquanto o estimador Chao de 2a ordem obteve o resultado de 5,12. Os índices de ShanonWeaver $\left(\mathrm{H}^{\prime}\right)$ e Equitabilidade $(\mathrm{J})$ mostraram que a diversidade e a distribuição das espécies na APA Municipal Tartarugas entre os meses de abril a agosto foram de 1,29 e 0,80 respectivamente. Este último, quanto mais próximo de 1 for o valor, mais uniforme é a distribuição de indivíduos dentro da comunidade.

A curva do coletor (Figura 5) mostra em vermelho os resultados obtidos e em azul os valores máximos e mínimos com intervalo de confiança de $95 \%$. A curva apresenta uma leve tendência à estabilização. Para que a mesma estagnasse, faltariam a captura de 1 a 1,5 espécies para mais e para menos, na qual seriam necessários a realização e continuação de estudos na área para que a mesma chegasse a sua estabilização. 


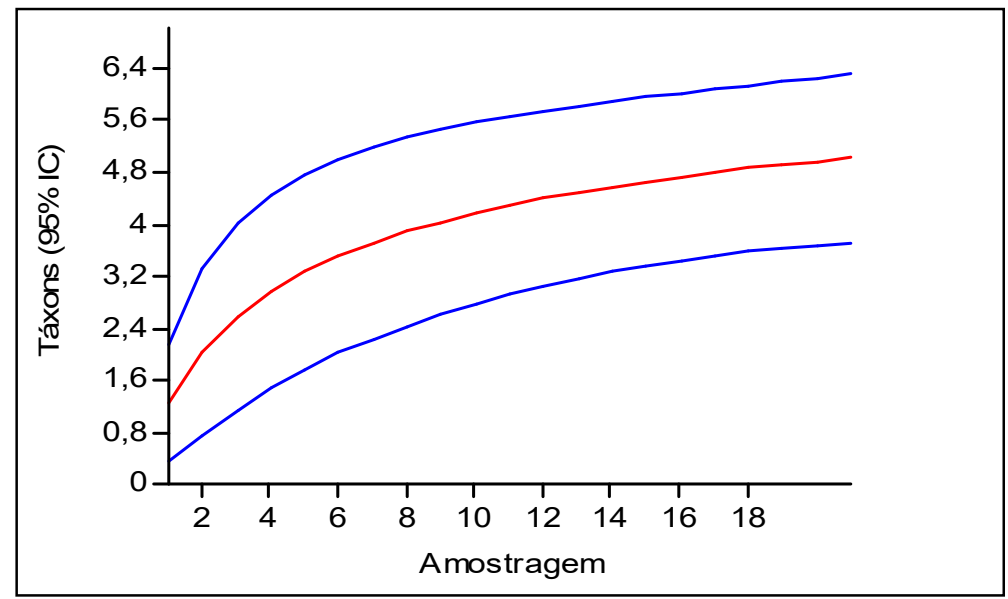

Figura 5: Curva do coletor obtida pelo método da rarefação.

Quanto ao sexo dos marsupiais, dos 04 indivíduos da espécie M. murina, todos (100\%) foram de fêmeas. Da espécie $M$. incanus, dos 08 capturados, 07 eram machos e 01 era fêmea. Já para a espécie Didelphis aurita, foi capturado um único indivíduo macho. Da ordem Rodentia, foram capturados 09 machos e 10 fêmeas. Durante o estudo, verificou-se a presença de seis filhotes recém-nascidos fixados nas mamas de uma fêmea da espécie $M$. murina e esta tinha reproduzido no período chuvoso (no mês de junho). A reprodução dos didelfídeos normalmente está sincronizada com o início do período chuvoso que é caracterizado por ser a estação com maior disponibilidade de alimento. Deste modo, os filhotes tornam-se independentes neste período devido não estarem amamentando-se (PASSAMANI, 2000; SOUZA, 2014; BEZERRA et al., 2015).

Na restinga da APA Tartarugas, verificou-se espécies frutíferas como Eugenia uniflora (pitanga vermelha), Schinus terebinthifolius (aroeira) e Allagoptera arenaria (Gomes) Kuntze (guriri) que frutificaram neste período com chuva. A armadilha com maior sucesso de captura foi a Tomahawk, com $56,4 \%$. Estas estavam localizadas em vegetação arbórea e arbustiva, onde capturaram 28 roedores, 11 marsupiais e 6 primatas, seguida da armadilha Sherman (30,7\%), que estava localizada em vegetação arbustiva e capturou 20 marsupiais e 4 roedores e a armadilha Pitfall (12,8\%), que capturou 3 marsupiais e 7 acidentais (Decapodas e Squamatas) em vegetação herbácea. Vale ressaltar que o total de armadilhas Sherman (20\%) e Interceptação e queda-Pitfall (25\%) eram inferiores às armadilhas Tomahawk (55\%).

Nenhuma espécie foi capturada exclusivamente em uma armadilha e das 3 espécies capturadas de marsupiais, a espécie Marmosops incanus tende a cair mais na armadilha Sherman devido possuir hábito arborícola, enquanto os roedores tendem a cair na armadilha Tomahawk, na qual estava localizada no solo. A Figura 6 mostra, por meio de um gráfico, a eficiência das armadilhas utilizadas na área da restinga.

Com relação à eficiência das iscas, a banana contribuiu para 29 capturas, sendo que, deste total, foram capturados 14 Didelphimorphias (12 cuícas e 2 gambás), 10 Rodentias e 5 Primatas. Já com a isca, a mistura (banana, farinha de milho, amendoim triturado e óleo de sardinha) contribuiu para a captura de 22 roedores e 18 marsupiais (cuícas). Ambas as ordens Didelphimorphia e Rodentia tiveram preferência pela isca mistura. Mas apesar da mistura ter capturado mais indivíduos, a isca banana obteve maior diversidade de animais. A Figura 7 demonstra a eficiência das iscas de banana e de mistura utilizadas. 


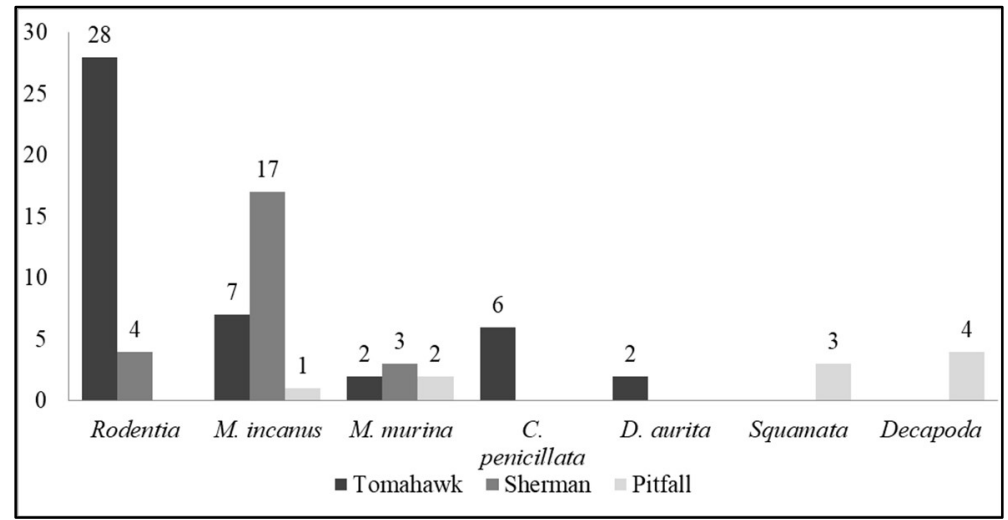

Figura 6: Eficiência das armadilhas Tomahawk, Sherman e pitfall na vegetação restinga.

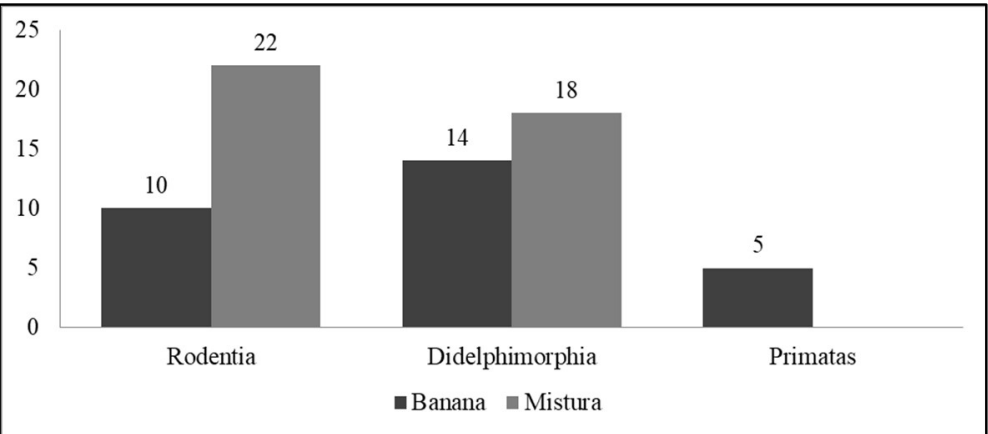

Figura 7: Eficiência das iscas banana e mistura na captura dos pequenos mamíferos.

As espécies de pequenos mamíferos não voadores encontrados na restinga da APA Municipal Tartarugas tiveram um resultado satisfatório, quando comparados a outros trabalhos realizados em áreas mais conservadas e maiores. No entanto, é importante ressaltar que a área possui dimensões pequenas de fragmentos de mata de restinga e um estado de recuperação não muito avançado. As espécies encontradas neste estudo diferem em partes com outras encontradas em trabalhos de mesmo cunho e realizadas em áreas maiores.

Dalmaschio et al. (2003) registraram, em um fragmento de Mata Atlântica no Município de Anchieta, Espírito Santo, a ocorrência de seis espécies de pequenos mamíferos, todas elas pertencentes a família Didelphidae, onde a espécie M. murina foi a mais abundante $(67,8 \%)$, seguida de Didelphis aurita $(18,9 \%)$. Passamani et al. (2005), no mesmo fragmento de Mata Atlântica, registraram a ocorrência de oito marsupiais, onde novamente a espécie $M$. murina foi a dominante $(31,2 \%)$, além da presença de cinco espécies da Ordem Rodentia.

Baitella et al. (2011) registraram a ocorrência de cinco espécies de marsupiais dentre elas as espécies Didelphis aurita e Marmosa murina, e nove espécies de roedores em áreas de restinga no Parque Estadual Paulo César Vinha, localizado no Município de Guarapari, Espírito Santo. Esta fica próxima a APA de Setiba, onde Carneiro (2011) amostrou um total de doze indivíduos da espécie Didelphis aurita, três da espécie $M$. incanus e dois indivíduos da espécie M. murina. Passamani (2000) e Palma (1996) citam a ocorrência de $M$. incanus em um fragmento de Mata Atlântica na localidade de Santa Teresa, Espírito Santo, e na Reserva Florestal da Companhia Vale do Rio Doce, com 36 e 128 indivíduos capturados, respectivamente.

Considerando-se os trabalhos supracitados, observa-se que as espécies $M$. murina e $D$. aurita representam, portanto, os pequenos mamíferos mais frequentes na maioria dos estudos realizados em 
fragmentos de Mata Atlântica e restinga no Estado do Espírito Santo. Enquanto neste estudo foram capturadas três espécies de marsupiais, sendo a espécie Marmosops incanus mais abundante e 19 indivíduos da Ordem Rodentia (todos ratos), em outras áreas estudadas, a riqueza destas espécies foi menor (com exceção das áreas estudadas por Palma (1996) e Passamani (2000)).

A alta frequência e abundância dos pequenos marsupiais e roedores na APA Municipal Tartarugas indicam que estes são oportunistas e podem ocupar diferentes habitats, inclusive em áreas com certa interferência humana (PASSAMANI et al., 2005; BETAT, 2012; MAGNUS et al., 2012). Outro ponto relevante é que todas as espécies de marsupiais capturados apresentam uma dieta onívora-insetívora. Estudos realizados por Souza et al. (2015) na APA Municipal Tartarugas indicam que, na área, há grande incidência do inseto crisopídeo, onde a tribo Leucochrysini Adams é a mais abundante. Além disso, a área apresenta espécies frutíferas, o que potencializa a presença de insetos, como os das ordens Coleóptera, Lepdoptera, Hymenoptera e Hemiptera, que foram observadas na área.

Em relação ao plano de manejo da restinga da APA Municipal Tartarugas realizado no ano de 2000, este cita como pequenos mamíferos que vem de encontro com o presente estudo os indivíduos das espécies Marmosa murina, Didelphis aurita e Calithrix penicillata, não havendo relatos de indivíduos da ordem Rodentia em relação aos ratos e dos indivíduos da espécie Marmosops incanus que, por sua vez, nesta pesquisa, foram os mais abundantes e que vem a ser um dado novo de ocorrência para a área e para o manejo da mesma.

Os resultados, de forma geral, foram satisfatórios. Segundo Pardini (2006), as espécies encontradas são importantes para a dispersão de sementes e fungos micorrízicos e por serem bioindicadores sinalizam alterações do ambiente em que habitam e influenciam a dinâmica florestal. Por isso, para a APA Municipal Tartarugas, a presença desses indivíduos é relevante para a conservação da dinâmica ecológica e natural da região, além da APA poder agir como um excelente abrigo para esses animais.

\section{CONCLUSÕES}

A restinga da Área de Proteção Ambiental Municipal Tartarugas apresenta grande riqueza de pequenos marsupiais e roedores, tendo em vista possuir dimensões pequenas e sofrer ações antrópicas ao seu entorno. Dentre os pequenos mamíferos não voadores, os indivíduos da espécie Marmosops incanus e da Ordem Rodentia apresentaram ser muito frequentes e muito abundantes, sendo capturados em maior quantidade em armadilhas Sherman e Tomahawk, respectivamente. De qualquer forma, os resultados obtidos no presente estudo indicam a importância da APA Municipal Tartarugas para a conservação de pequenos marsupiais e roedores da Mata Atlântica. Dessa forma, sugere-se que a APA Municipal Tartarugas seja conservada e monitorada para que novos estudos possam ser realizados na mesma, sendo imprescindíveis ações mitigadoras como desenfrear a ocupação humana ao seu redor, além do plantio de espécies nativas do ecossistema restinga, a fim de dar suporte e permanência às espécies encontradas e demais outras. 


\section{REFERÊNCIAS}

ANCHIETA. Câmara Municipal de Anchieta. Lei Municipal no. 008 de 18 de Junho de 1998 com base no Art. 46, § 3ㅇ da Lei Orgânica Municipal e Art. 66, § 3 da Constituição Estadual. Estabelece a preservação da área destinada à desova de tartarugas marinhas. Anchieta: DOE, 1998.

BAITELLA, F. M.; ROCHA, M. F.. Pequenos mamíferos em uma área de restinga no estado do espírito santo. In: CONGRESSO DE ECOLOGIA DO BRASIL, 10. Anais. São Lourenço: Sociedade Brasileira de Ecologia do Brasil, 2011.

BETAT, V. S.. Distribuição da subfamília sigmodontinae (mammalia, rodentia) no Rio Grande do Sul, Brasil. Monografia (Especialização em Diversidade e Conservação da Fauna) - Universidade Federal do Rio Grande do Sul, Porto Alegre, 2012.

BEZERRA, A. C.; GEISE, L.. O estado da arte de Marmosops incanus (Lund,1840) (Didelphimorphia, Didelphidae): uma síntese. RJ. Boletim da Sociedade Brasileira de Mastozoologia, v.73, p.65-86, 2015.

BONVICINO, C. R.; OLIVEIRA, J. A.; D'ANDREA, P. S.. Guia dos Roedores do Brasil, com chaves para gêneros baseadas em caracteres externos. Rio de Janeiro: Centro Pan-Americano de Febre Aftosa, 2008.

MMA. Ministério do meio ambiente. Livro vermelho da fauna Brasileira ameaçada de extinção Mamíferos. Brasília: Fundação Biodiversidades, 2008.

MMA. Ministério do Meio Ambiente. Conselho Nacional do Meio Ambiente. Resolução CONAMA n. 10, de 1 de outubro de 1993. Estabelece os parâmetros básicos para análise dos estágios de sucessão de Mata Atlântica. Brasília: MMA, 1993.

MMA. Ministério do meio ambiente. Mata Atlântica: patrimônio nacional dos brasileiros. Brasília: Instituto Brasileiro de Meio Ambiente, 2010.

MMA. Ministério do meio ambiente. Mapeamentos para a conservação e recuperação da biodiversidade na Mata Atlântica: em busca de uma estratégia espacial integradora para orientar ações aplicadas. Brasília: Instituto Brasileiro de Meio Ambiente, 2013.

CARNEIRO. P. H. N. F. Avaliação do efeito de rodovias sobre a fauna em áreas de restinga do sudeste do Brasil. ES. Dissertação (Mestrado em Ecologia) - Universidade de Vila Velha, Vila Velha, 2011.

DALMASHIO, J.; PASSAMANI, M.. Aspectos da ecologia de marmosa murina (Linnaeus, 1758) (Mammalia, Didelphimorphia), em uma região de Mata Atlântica no estado do Espírito Santo. Revista Biotemas, Florianópolis, v.16, n.2, p.145-158, 2003.

EA. Estudo Ambiental. Plano de manejo da Área de Proteção Ambiental Municipal Tartarugas. Vitória: PSG Equilibrium do Brasil Ltda, 2000.

GARCIA, Q. S.; LUCAS, N. M. C.. Germinative behaviour of Jacquinia brasiliensis seeds. Revista Brasileira de Botânica, v.17, n.1, p.13-18, 1994.
LESSA, I. C. M.; RIBEIRO, T. T. L.; COSTA, D. P.; MANGOLIN, R; ENRICE, M. C.; BERGALLO, H. G.. Riqueza de pequenos mamíferos e complexidade de habitats em restingas do sudeste brasileiro. In: CONGRESSO DE ECOLOGIA DO BRASIL, 8. Anais. Caxambu: Sociedade Brasileira de Ecologia do Brasil, 2007.

MAGNUS, L. Z.; CÁCERES, N. C.. Efeito do tamanho de área sobre a riqueza e composição de pequenos mamíferos da floresta atlântica. Revista Mastozoología Neotropical, v.19, n.2, p.243-258, 2012.

MONTES, M. A.. História da ocupação da planície costeira do RS pelo roedor Deltamys kempi- tentativa de reconstrução pela análise do mtDNA. Dissertação (Mestrado em Genética e Biologia Celular) - Universidade Federal do Rio Grande do Sul, Porto Alegre, 2003.

PALMA, A. R. T.. Separação de nichos entre pequenos mamíferos de mata atlântica. Dissertação (Mestrado em Ciências Biológicas) - Universidade Estadual de Campinas, Campinas, 1996.

PARDINI, R.; UMETSU, F.. Pequenos mamíferos nãovoadores da Reserva Florestal do Morro Grande: distribuição das espécies e da diversidade em uma área de Mata Atlântica. Revista Biota Neotropica, v.6, n.2, p.1-22, 2006. DOI: https://doi.org/10.1590/S1676-06032006000200007

PASSAMANI, M.. Análise da comunidade de marsupiais em Mata Atlântica de Santa Teresa, Espírito Santo. Boletim do Museu de Biologia Mello Leitão, v.11, n.12, p.215-228, 2000.

PASSAMANI, M.; DALMASHIO, J.; LOPES, S. A.. Mamíferos não-voadores em áreas com predomínio de Mata Atlântica da Samarco mineração S.A., município de Anchieta, Espírito Santo. Revista Biotemas, Florianópolis, v.18, n.1, p.135-149, 2005.

PESSÔA, F. S.. Comunidades de pequenos mamíferos no estado do Rio de Janeiro. Dissertação (Mestrado em Ciências Biológicas) - Universidade do Estado do Rio de Janeiro, Rio de Janeiro, 2009.

RABELLO, H.; LACCHINE, P.S.; PINHEIRO, P.C.; MOULIN, E.; VERISSIMO, A.. Levantamento da mastofauna nas áreas de reserva legal da Fazenda Brunoro agro - avícola, situada em venda nova do Imigrante, Espírito Santo, Brasil. In: CONGRESSO DE ECOLOGIA DO BRASIL, 9. Anais. São Lourenço: Sociedade Brasileira de Ecologia do Brasil, 2016.

REIS, N. R.; PERACCHI, A. L.; PEDRO, W. A.; LIMA, I. P.. Mamíferos do Brasil. Londrina: Universidade Estadual de Londrina, 2006.

SANTOS, B. S.; MENDES, S. L.. Evolução da Paisagem no Parque Estadual Paulo César Vinha, Guarapari-ES. In: SIMPÓSIO BRASILEIRO DE SENSORIAMENTO REMOTO, 15. Anais. Curitiba: Instituto Nacional de Pesquisas Espaciais, 2011. p.6201-6208.

SOUZA, C. V.. Dinâmica populacional de roedores e marsupiais no extremo norte da Mata Atlântica. 
Monografia (Bacharelado em Ciências Biológicas) -

Universidade Federal da Paraíba, João Pessoa, 2015.

SOUZA, H. Z. S.; GUIMARÃES, V. A.; SILVA FILHO, G.

Crisopídeos (insecta, neuroptera, chrysopidae) da Área de

Proteção Ambiental (APA) Municipal Tartarugas, Anchieta,

Espírito Santo. Monografia (Bacharelado o em Ciências
Biológicas) - Centro Universitário São Camilo, Cachoeiro de Itapemirim, 2015.

SOSMA; INPE. Fundação SOS Mata Atlântica; Instituto Nacional de Pesquisas Espaciais. Atlas dos remanescentes florestais da Mata Atlântica período 2013 a 2014. São Paulo: Instituto Nacional de Pesquisas Espaciais, 2015.

A CBPC - Companhia Brasileira de Produção Científica (CNPJ: 11.221.422/0001-03) detém os direitos materiais desta publicação. Os direitos referem-se à publicação do trabalho em qualquer parte do mundo, incluindo os direitos às renovações, expansões e disseminações da contribuição, bem como outros direitos subsidiários. Todos os trabalhos publicados eletronicamente poderão posteriormente ser publicados em coletâneas impressas sob coordenação da Sustenere Publishing, da Companhia Brasileira de Produção Científica e seus parceiros autorizados. Os (as) autores (as) preservam os direitos autorais, mas não têm permissão para a publicação da contribuição em outro meio, impresso ou digital, em português ou em tradução. 